\title{
Propriedades de adesivo aplicado em painéis a partir da substituição por lignossulfonato do processo sulfito
}

\author{
Properties of adhesive apllied to panels from the substitution for lignosulfonate of the sulfite \\ process
}

\author{
Gilmar Correia Silva ${ }^{\mathrm{I}}$, Roberto Carlos Costa Lelis ${ }^{\mathrm{II}}$, Gisely de Lima Oliveira ${ }^{\mathrm{III}}$, Bruno Couto da Silva ${ }^{\mathrm{III}}$, \\ Wagner César da Silva Lossano ${ }^{\text {IV }}$, Heber dos Santos Abreu ${ }^{\text {II }}$
}

\begin{abstract}
Resumo
Considerando a indústria de painéis aglomerados, a maior parte utiliza adesivos sintéticos, especialmente, à base de ureia-formaldeído, e nesse sentido, estudos que englobam as características de materiais alternativas para a indústria de painéis tornam-se importantes, especialmente quando se considera o custo final dos produtos gerados. O presente trabalho teve como objetivo geral avaliar as alterações na estrutura química do adesivo que pudessem provocar possíveis modificações nas suas propriedades ligantes em função da substituição do adesivo ureia-formaldeído pelo lignossulfonato. Para tanto, foi determinada a composição química elementar do lignossulfonato e suas ligações químicas por meio da espectroscopia de infravermelho (IV) e ressonância magnética nuclear (RMN), puro e em composição com diferentes catalisadores; as propriedades da ureia-formaldeído e suas modificações como $\mathrm{pH}$, viscosidade, tempo de formação de gel e viscosidade. A análise de RMN mostrou, para o lignossulfonato, o mesmo padrão geralmente obtido para derivados de lignina em suas ligações químicas. A análise química elementar mostrou altos teores de $\mathrm{Mg}, \mathrm{Ca}$ e $\mathrm{Na}$. A adição de lignossulfonato sobre a ureia-formaldeído causou acidificação no adesivo e redução dos valores de viscosidade. O efeito sobre o tempo de formação de gel também foi afetado, entretanto, verificou-se que a metodologia para esse tipo de polímero, deve ser readequada em relação ao método tradicional, submetendo o mesmo à temperatura superior a $90^{\circ} \mathrm{C}$. Os resultados permitiram concluir que é possível a utilização do lignossulfonato em substituição ao adesivo ureia-formaldeído considerando o painel de madeira aglomerada.
\end{abstract}

Palavras-chave: Licor sulfito; Adesivos naturais; Adesivos sintéticos

\begin{abstract}
Considering the agglomerated panel industries, most of them use synthetic adhesives, especially urea-formaldehyde, and to this end, studies covering the characteristics of alternative materials for the panel industry become important, especially when considering the final cost of the products generated. The present work had as general objective to evaluate the alterations in the chemical structure of the adhesive that could cause possible modifications in its binder properties as a function of the substitution of the adhesive urea-formaldehyde by the lignosulfonate. Therefore, it was determined the basic chemical composition of the lignosulfonate and its chemical bonds by infrared spectroscopy (IR) and the nuclear magnetic resonance (NMR), pure and in composition with different catalysts; the properties of urea-formaldehyde and its modifications such as $\mathrm{pH}$, viscosity, gel time and viscosity. NMR analysis showed the lignosulfonate to the same pattern usually obtained for lignin derivatives in their chemical bonds. The elementary chemical analysis showed high $\mathrm{Mg}, \mathrm{Ca}$ and $\mathrm{Na}$. The addition of lignosulfonate on urea-formaldehyde caused the adhesive acidification and reduction of viscosity values. The effect on gel time was also affected. However, it was found that the methodology for this type of polymer should be adequate compared to the traditional method, submitting the same to temperatures above $90^{\circ} \mathrm{C}$. The results showed that it is possible to use lignosulfonate to replace the urea-formaldehyde adhesive.
\end{abstract}

Keywords: Sulfite liquor; Natural adhesive; Synthetic adhesive

\footnotetext{
I Engenheiro Florestal, Dr., Professor do Departamento de Fitotecnia e Zootecnia, Universidade Estadual do Sudoeste da Bahia, Estrada do Bem Querer, km 04, Caixa Postal 95, CEP 45083-900, Vitória da Conquista (BA), Brasil. gilmarsilva@uesb.edu.br (ORCID: 0000-0002-8931-8773)

II Engenheiro Florestal, Dr., Professor do Departamento de Produtos Florestais, Universidade Federal Rural do Rio de Janeiro, BR 465, km 07, CEP 23890-000, Seropédica (RJ), Brasil. lelis@ufrrj.br (ORCID: 0000-0003-2923-3839)/abreu@ufrrj.br (In Memoriam)

III Engenheiro(a) Florestal, MSc., Doutorando(a) em Ciências Ambientais e Florestais pelo Programa de PósGraduação em Ciências Ambientais e Florestais, Universidade Federal Rural do Rio de Janeiro, BR 465, km 07, CEP 23890-000, Seropédica (RJ), Brasil. gyoliveira@gmail.com (ORCID: 0000-0001-6253-4057)/brunoengf@gmail.com (ORCID: 0000-0002-7670-9628)

IV Químico, Pesquisador Autônomo, Universidade Federal Rural do Rio de Janeiro, BR 465, km 07, CEP 23890-000, Seropédica (RJ), Brasil. vamp-r@hotmail.com (ORCID: 0000-0002-4954-3933)
} 


\section{Introdução}

O desenvolvimento da indústria de painéis de madeira foi impulsionado pelo surgimento dos adesivos sintéticos, sendo empregados inicialmente aqueles à base de ureia-formaldeído, cuja utilização atual, ainda representa a grande maioria. A ABNT NBR 14810-1 (2013) define o termo adesivo ou resina como utilizada com o objetivo de aderir partículas de madeira em um painel, podendo ser orgânica ou inorgânica.

Gonçalves (2012) descreve as resinas à base de ureia-formaldeído como de baixa resistência à umidade, e obtidas pela condensação de formaldeído com a ureia. Esta substância, por ser oriunda de derivados de petróleo, apresenta um custo elevado, interferindo no custo total dos painéis.

Melo (2009) destaca que em $90 \%$ de todos os painéis aglomerados produzidos no mundo é utilizado esse tipo de resina. E Carvalho, Lelis e Nascimento (2014) ratificam que a ureia-formaldeído como produto obtido de fonte não renovável, apresenta além da intolerância à umidade, uma alta emissão de formaldeído.

Como produtos relativamente instáveis, as resinas sintéticas à base de formaldeído, apresentarão viscosidade e tempo de vida, em função da temperatura e das etapas de condensação.

Para Lelis (1995), pesquisas que busquem matérias-primas alternativas para a indústria de painéis são importantes, porque o custo da aquisição de resinas sintéticas representa um componente de peso no custo total do produto. Nesse contexto, pesquisas que viabilizem matérias-primas alternativas para a indústria de painéis de madeira que reduzam o custo são importantes, uma vez que o valor de aquisição de resinas sintéticas representa um componente significativo em relação ao custo total do produto.

De acordo com Goda et al. (2000), o lignossulfonato ou licor sulfito refere-se a um subproduto rico em lignina gerado a partir da polpação da madeira pelos processos ácidos sulfito ou bissulfito em fábricas de celulose e papel, também sendo possível obtê-lo pelo processo de polpação alcalino chamado kraft. Ainda corroboram a justificativa para substituição de adesivos comerciais por adesivos à base de polímeros naturais ou em composição, à problemática da emissão de substâncias tóxicas, neste caso, o formaldeído para a atmosfera.

Dentre as propriedades de lignossulfonatos, destacam-se as tensoativas (redução da tensão superficial ou interfacial, a detergência, a umectância ou molhabilidade), aglomerantes, dispersantes, emulsificantes, e a de combinação com proteínas. Algumas dessas propriedades podem potencializar a sua utilização em associação ou com substâncias à base de formaldeído na produção de painéis de madeira ou não, como mostram pesquisas realizadas inicialmente na década de 60 na Dinamarca e Finlândia, citadas por Iwakiri (2005). Estas pesquisas por detectarem alguns problemas relacionados às propriedades mecânicas dos painéis promoveram a substituição do adesivo lignossulfonato por resinas sintéticas.

De acordo com El Mansouri e Salvató (2006), os lignossulfonatos são ligninas técnicas mais importantes em quantidade, do ponto de vista comercial. Além disso, são considerados de baixo valor agregado. Dado o potencial de utilização do lignossulfonato, o autor continua, destacando que, ultimamente, há uma série de operações de purificação associadas ao processo sulfito, sendo possível a produção de lignossulfonatos em pó, através da fermentação e evaporação do etanol para eliminar açúcar e redução de sais.

Guimarães Junior et al. (2013) citam a utilização de painéis particulados à base de madeira em contínua evolução tecnológica, com destaque às pesquisas direcionadas a um maior e melhor aproveitamento desses produtos, sendo importante o estudo dos parâmetros que irão influenciar a qualidade dos mesmos. Assim, pode-se afirmar que a qualidade dos painéis de madeira está em função dos estudos realizados previamente sobre composições das suas diversas variáveis de produção.

De acordo com Hernandez (2007), na obtenção do lignossulfonato sulfito, as matérias-primas lignocelulósicas são colocadas para reagir com uma mistura de dióxido de enxofre e uma base de sulfito, em altas temperaturas e $\mathrm{pH}$ baixo. Os licores residuais contêm majoritariamente polímeros de lignina sulfonada (lignossulfonatos), contendo em média de 70 a $75 \%$ destes compostos e as propriedades dos lignossulfonatos são afetadas de acordo com a matéria-prima utilizada no processo, em que madeiras de folhosas têm uma massa molar menor que os lignossulfonatos obtidos das madeiras de coníferas. 
O efeito do tipo e da quantidade de adesivo, sobre a composição dos painéis de madeira, é significativo e o aumento do teor de resina causa um incremento nas propriedades mecânicas e na estabilidade dimensional do painel (RAZERA, 2006).

Dentre os fatores que influenciam na colagem de madeiras e painéis reconstituídos, Iwakiri et al. (2005) citam um conjunto que deve ser avaliado. São eles: características físico-químicas do adesivo; composição e características da madeira; procedimentos empregados na colagem; e, condições de uso do produto colado.

Em se tratando de painéis aglomerados, além de outras variáveis, as características físico-químicas do adesivo são normalmente analisadas previamente para verificar o possível comportamento do mesmo em relação ao processo de adesão. São elas de acordo com Iwakiri et al. (2005):

a) Viscosidade: definida pela resistência ao fluxo livre entre as camadas de uma matéria ou, ainda, a grandeza que expressa o atrito entre as moléculas de um fluido livre e que se manifesta através do escoamento.

b) Tempo de formação de gel/tempo de gelatinização/"gel time": corresponde ao período transcorrido desde o preparo do adesivo até a sua aplicação, incluindo a composição com aditivos. Sua importância, está na vida útil e reatividade do adesivo.

c) Teor de sólidos: representa a quantidade de sólidos existentes no adesivo que é formado por componentes sólidos e líquidos, estes últimos são volatilizados durante a prensagem a quente, ocorrendo o primeiro processo de cura e solidificação da resina.

d) $\mathrm{pH}$ : com a determinação feita diretamente por meio do pHmetro, e, tem importância para madeira e para o adesivo, já que a resina não deve ter limites de $\mathrm{pH}$ fora da faixa de 2,5 a 11,0 , pois pode resultar na degradação das fibras da madeira, e quando utilizando o $\mathrm{pH}$ muito baixo, pode provocar espuma na mistura, prejudicando a colagem. Cada resina tem uma faixa para cura, em meio ácido ou alcalino.

Para Camargo (2003), a utilização do lignossulfonato como substituinte em resinas fenólicas pode ser devido ao mesmo ser um componente oriundo de fonte renovável, já que se trata de um derivado de lignina extraído do licor negro (efluente da indústria de papel); por implicar em um menor custo para o produto final; e por possuir propriedades de superfície ativa, o que poderia resultar em um compósito com características positivas. Além disso, o aumento do custo do fenol contribui para que se substitua esse componente por outros, desde que não haja modificações das propriedades.

Considerando o exposto, o objetivo geral deste trabalho foi avaliar as modificações das propriedades químicas e ligantes ocorridas em função da substituição do adesivo ureia-formaldeído pelo lignossulfonato.

\section{Material e métodos}

Análise das propriedades químicas do lignossulfonato

Análise química elementar do lignossulfonato

Foram utilizadas três amostras do lignossulfonato que passaram por processo de maceração e misturadas a $45 \%$ em água destilada. Após $24 \mathrm{~h}$ em repouso para sua total diluição, foram encaminhadas ao Laboratório de Absorção Atômica do Departamento de Solos da UFRRJ.

Os seguintes elementos foram analisados através do equipamento Spectra AA Varian 55B, Atomic Absortion Spectrometer: $\mathrm{Cu}, \mathrm{Ni}, \mathrm{Fe}, \mathrm{Cd}, \mathrm{Pb}, \mathrm{Ca}, \mathrm{Mg}, \mathrm{Na}, \mathrm{K}$ e $\mathrm{P}$.

Espectroscopia no infravermelho (IV) do lignossulfonato

Os espectros no IV foram obtidos no espectrofotômetro Varian 640 IR FT- IR Spectrometer, no Laboratório de Química da Madeira da UFRRJ. Foi realizada análise de IV em três amostras de lignossulfonato puro em condição sólida, obtidos através do modo de transmissão e atribuições, objetivando a caracterização dos espectros para determinar a composição química do material. 
Foram utilizados $2 \mathrm{mg}$ de amostra de lignossulfonato na forma de pó, semelhante à granulometria de um talco, e $100 \mathrm{mg}$ de brometo de potássio $(\mathrm{KBr})$. Posteriormente, a mistura foi prensada formando uma pastilha que foi analisada no espectrofotômetro.

As frequências das absorções foram medidas em centímetros recíprocos $\left(\mathrm{cm}^{-1}\right)$ com varreduras de 4000 a $300 \mathrm{~cm}^{-1}$.

Ressonância magnética nuclear (RMN) do lignossulfonato

Os espectros dos extratos foram obtidos em um espectrômetro VARIAN Mercury plus ( $400 \mathrm{MHz}$ para ${ }^{1} \mathrm{H}$ ) ampliado na faixa de 100 a $160 \mathrm{ppm}$. Os deslocamentos químicos (ppm) foram referenciados no $\mathrm{RMN}^{13} \mathrm{C}$ no Laboratório de Ressonância Magnética Nuclear em Solução, da Central de Ressonância Magnética (CeRM), do Departamento de Química (DEQUIM) da UFRRJ.

Após sua maceração e diluição do lignossulfonato em água destilada a $45 \%$, foram realizadas triplicatas de quatro amostras de lignossulfonato puro e modificado com diferentes catalisadores. Após 24 $\mathrm{h}$, as amostras foram liofilizadas e encaminhadas à CeRM. Para preparo das amostras, momentos antes das análises foi utilizado o dimetilsulfóxidoou sulfóxido de dimetilo $\left(\mathrm{CH}_{3}\right)_{2} \mathrm{SO}$, conhecido como DMSO, solvente aprótico e polar.

O uso da RMN permitiu parte da verificação estrutural do lignossulfonato puro e associado aos catalisadores testados, assim como as técnicas espectroscópicas avançadas na composição estrutural das substâncias orgânicas. A técnica forneceu valores de correlação dos deslocamentos químicos dos carbonos e respectivos hidrogênios das substâncias.

Caracterização dos adesivos

Os adesivos utilizados neste trabalho foram originários de doação de empresas. Aureia-formaldeído (UF) registrada comercialmente como Cascamite MDP 102 na forma líquida foi doada pela Momentive. E o lignossulfonato (LS), em forma de pó, pela empresa Melbar.

Preparação dos adesivos

A ureia-formaldeído, na forma líquida, teve seus parâmetros avaliados de acordo com os procedimentos a seguir. Já o lignossulfonato em pó, foi diluído em água destilada na proporção de 45:55\%. Para compor os diferentes tratamentos em cada fase do experimento, a mesma proporção de diluição do lignossulfonato foi repetida. Os tratamentos iniciais foram compostos pela seguinte proporção adesiva de ureia-formaldeído (UF)/lignossulfonato (LS): 100\% UF; 80:20; 60:40; 40:60; 20:80; 100\% LS.

$\mathrm{pH}$ do adesivo

Para a ureia-formaldeído o $\mathrm{pH}$ foi determinado diretamente em três amostras de cada tratamento descrito anteriormente com auxílio de um pHmetro digital calibrado em solução tampão 4,0 e 7,0 com leitura registrada após quatro minutos de contato do eletrodo com a solução.

Tempo de formação do gel

Para a ureia-formaldeído, $10 \mathrm{~g}$ da solução foi adicionada em três tubos de ensaios e em seguida adicionado uma solução de $2 \%$ de sulfato de amônia a $24 \%$ (catalisador) com base no teor de sólidos contidos no adesivo. A mistura foi homogeneizada com bastão de vidro em banho-maria à temperatura de $90^{\circ} \mathrm{C}$ até o ponto de endurecimento. $\mathrm{O}$ tempo necessário para que a mistura alcançasse a fase gel expressou o tempo de formação de gel.

Para o lignossulfonato, o mesmo procedimento foi realizado após sua diluição, e nas composições adesivas com a ureia-formaldeído, de acordo com cada composição estabelecida por tratamento. 
Para o lignossulfonato puro (100\% LS), o catalisador utilizado foi o formaldeído a $37 \%$ na proporção de $20 \%$ sobre o teor de sólidos contidos na solução de lignossulfonato. Para a ureia-formaldeído pura ( $100 \%$ UF) e em composição com o lignossulfonato nos demais tratamentos, foi utilizado $2 \%$ de sulfato de amônia a $24 \%$.

Viscosidade

A viscosidade está relacionada com teor de sólidos, peso molecular, temperatura ambiente e tempo de armazenamento da resina. O procedimento foi realizado de acordo com a norma ASTM D1200 (2014).

Para a ureia-formaldeído, lignossulfonato diluído em água destilada a $45 \%$, e as diferentes composições de tratamentos, a viscosidade foi determinada utilizando-se copo Ford $\mathrm{n}^{\circ} 4$, sendo adicionado aproximadamente $130 \mathrm{ml}$ do adesivo no copo e o tempo necessário para o escoamento da solução pelo copo foi registrado.

O valor da viscosidade foi obtido de acordo com a equação abaixo:

$$
\mathrm{V}=\left(3,82 \cdot \mathrm{t}^{-} 17,28\right) \cdot \mathrm{d}
$$

Em que: $\mathrm{V}=$ viscosidade dinâmica, expressa em mPa.s; $\mathrm{t}=$ tempo de escoamento, em segundos; $\mathrm{e} d=$ densidade do adesivo, em $\mathrm{g} / \mathrm{cm}^{3}$.

Teor de sólidos

O teor de sólidos foi determinado de acordo com Brito (1995). Foram realizadas três amostras para cada tratamento, utilizando $5 \mathrm{~g}$ para cada amostra.

Para cada tratamento, $5 \mathrm{~g}$ do adesivo foram colocados em cadinhos de peso conhecidos que foram levados posteriormente à estufa aquecida a $103 \pm 2^{\circ} \mathrm{C}$ por $24 \mathrm{~h}$.

O teor de sólidos foi calculado através da equação:

$\mathrm{TS}=(\mathrm{PS} \mid \mathrm{PU}) .100$

Em que: $\mathrm{TS}=$ teor de sólidos, expresso em \%; PS = peso seco, em g; e PU = peso inicial, em g.

Análise dos Dados

Os dados provenientes das análises dos adesivos foram dispostos em planilha e analisados por meio de estatística descritiva, com média, coeficiente de variação e desvio padrão, já que se tratou de um conjunto em triplicatas do mesmo universo amostral. O programa utilizado foi o Sisvar de domínio da Universidade Federal de Lavras.

\section{Resultados e Discussão}

\section{Caracterização dos adesivos}

As características dos adesivos ureia-formaldeído, lignossulfonato e misturas entre eles com os respectivos catalisadores são apresentados nos próximos itens.

Caracterização de ureia-formaldeído e lignossulfonato

$\mathrm{pH}$ dos adesivos 
Silva, G. C.; Lelis, R. C. C.; Oliveira, G. L.; Silva, B. C.; Lossano, W. C. S.; Abreu, H. S. 327

Os valores de $\mathrm{pH}$ para as composições de adesivos utilizados na produção dos painéis aglomerados são apresentados na Tabela 1 .

Tabela 1- pH médio da composição dos adesivos.

Tabl 1-Mean $\mathrm{pH}$ of the composition of the adhesive.

\begin{tabular}{lccc}
\hline \multirow{2}{*}{ Tratamento } & \multicolumn{2}{c}{ Composição do Adesivo (\%) } & \multirow{2}{*}{$\mathbf{p H}$} \\
\cline { 2 - 3 } & $\mathbf{U F}$ & $\mathbf{L S}$ & 8,31 \\
\hline 1 & 100 & 0 & 5,31 \\
2 & 80 & 20 & 4,19 \\
3 & 60 & 40 & 3,59 \\
4 & 40 & 60 & 3,31 \\
5 & 20 & 80 & 3,00 \\
6 & 0 & 100 & \\
\hline
\end{tabular}

Em que: $U F=$ ureia-formaldeído; $\mathrm{LS}=$ lignossulfonato

Os lignossulfonatos apresentam valores de $\mathrm{pH}$ bastante ácidos. Já o adesivo ureia-formaldeído apresentou valor médio de 8,31 , sendo que os valores foram diminuindo à medida que os mesmos foram modificados com maiores percentagens de lignossulfonatos.

$\mathrm{O} \mathrm{pH}$ é uma variável importante, pois regula o processo de endurecimento de um adesivo durante a prensagem.

Tempo de formação de gel

Os valores de tempo de formação de gel para as composições de adesivos utilizados na produção dos painéis aglomerados são apresentados na Tabela 2.

Tabela 2 - Tempo de formação de gel (TG) para diferentes composições de adesivos.

Table $2-$ Gel formation time (TG) for different compositions of adhesives.

\begin{tabular}{cccccc}
\hline \multirow{2}{*}{ Tratamento } & \multicolumn{2}{c}{$\begin{array}{c}\text { Composição do Adesivo } \\
(\%)\end{array}$} & & Catalisador/ & TG \\
\cline { 2 - 3 } & UF & LS & Endurecedor & (minutos) \\
\hline 1 & 100 & 0 & & Sem adição & $\mathrm{ND}$ \\
2 & 100 & 0 & & $2 \%\left(\mathrm{NH}_{4}\right)_{2} \mathrm{SO}_{4}$ a $24 \%$ & 2,10 \\
3 & 80 & 20 & & $2 \%\left(\mathrm{NH}_{4}\right)_{2} \mathrm{SO}_{4}$ a $24 \%$ & $\mathrm{ND}$ \\
4 & 60 & 40 & & $2 \%\left(\mathrm{NH}_{4}\right)_{2} \mathrm{SO}_{4}$ a $24 \%$ & $\mathrm{ND}$ \\
5 & 40 & 60 & & $2 \%\left(\mathrm{NH}_{4}\right)_{2} \mathrm{SO}_{4}$ a $24 \%$ & $\mathrm{ND}$ \\
6 & 20 & 80 & & $2 \%\left(\mathrm{NH}_{4}\right)_{2} \mathrm{SO}_{4}$ a $24 \%$ & $\mathrm{ND}$ \\
7 & 0 & 100 & & $20 \%$ Formaldeído a $37 \%$ & $\mathrm{ND}$ \\
\hline
\end{tabular}

Em que: ND = não foi observada a formação de gel após 10 minutos, de acordo com a metodologia; UF = ureiaformaldeído; LS = lignossulfonato.

$\mathrm{O}$ valor encontrado de tempo de gel para o adesivo ureia-formaldeído com $2 \%\left(\mathrm{NH}_{4}\right)_{2} \mathrm{SO}_{4}$ a $24 \%$ está de acordo com os encontrados na literatura. Almeida (2010) e Viera (2010) encontraram valor médio de 2,06 minutos.

Vieira (2014) avaliando a adição de extratos tânicos sobre o adesivo ureia-formaldeído, encontrou para este último, o valor médio de 1,16 minutos para formação do tempo de gel. 
Não foi possível a obtenção de tempo de gel para os adesivos ureia-formaldeído modificados com lignossulfonatos, evidenciando que os lignossulfonatos interferem na reatividade da mistura. Entretanto, a metodologia aplicada pode ter interferido, considerando a temperatura de exposição de $90^{\circ} \mathrm{C}$ para formação do tempo de gel. Talvez uma maior temperatura evidencie essa propriedade para o tipo de composição estudada neste trabalho.

Viscosidade

Os valores médios de viscosidade para as composições adesivas são apresentados na Tabela 3.

Tabela 3 -Viscosidade para diferentes composições adesivas.

Table 3 - Viscosity for different adhesive compositions.

\begin{tabular}{lccc}
\hline \multirow{2}{*}{ Tratamento } & \multicolumn{2}{c}{ Composição do Adesivo (\%) } & Viscosidade \\
\cline { 2 - 3 } & UF & LS & (mPa.s) \\
\hline 1 & 100 & 0 & 346,71 \\
2 & 80 & 20 & 200,00 \\
3 & 60 & 40 & 148,94 \\
4 & 40 & 60 & 117,54 \\
5 & 20 & 80 & 98,38 \\
6 & 0 & 100 & 57,48 \\
\hline
\end{tabular}

Em que: UF = ureia-formaldeído; LS = lignossulfonato

Os valores médios de viscosidade do adesivo ureia-formaldeído encontram-se dentro da faixa ideal para fabricação de aglomerados.

A substituição de parte do adesivo ureia-formaldeído por lignossulfonato favoreceu para diminuição dos valores de viscosidade, uma vez que os lignossulfonatos puros apresentaram valores bem baixos de viscosidade.

Teor de sólidos

Os valores médios para o teor de sólidos para as diferentes composições adesivas são apresentados na Tabela 4.

Tabela 4 - Teor de sólidos (TS) para diferentes composições adesivas.

Table 4 - Solid contents (TS) for different adhesive compositions.

\begin{tabular}{lccc}
\hline \multirow{2}{*}{ Tratamento } & \multicolumn{2}{c}{ Composição do Adesivo (\%) } & TS \\
\cline { 2 - 3 } & UF & LS & (\%) \\
\hline 1 & 100 & 0 & 67,30 \\
2 & 80 & 20 & 62,19 \\
3 & 60 & 40 & 56,60 \\
4 & 40 & 60 & 48,94 \\
5 & 20 & 80 & 47,92 \\
6 & 0 & 100 & 42,08 \\
\hline
\end{tabular}

Em que: UF = ureia-formaldeído; $\mathrm{LS}=$ lignossulfonato.

O teor de sólidos do adesivo ureia-formaldeído foi de $67,30 \%$ e, naturalmente, com a adição de lignossulfonato à ureia-formaldeído, os valores foram reduzindo.

Análise química elementar do lignossulfonato 
A Tabela 5 apresenta os valores médios dos elementos químicos presentes no lignossulfonato sem modificação e diluído a $45 \%$.

Tabela 5 -Elementos químicos apresentados pelo lignossulfonato in natura e diluído a $45 \%$ em água.

Table 5 -Chemical elements presented by lignosulfonate raw and diluted to $45 \%$ in water.

\begin{tabular}{cccccccccc}
\hline \multicolumn{10}{c}{ Elementos Químicos (mg/L) } \\
\hline $\mathrm{Cu}$ & $\mathrm{Ni}$ & $\mathrm{Fe}$ & $\mathrm{Cd}$ & $\mathrm{Pb}$ & $\mathrm{Ca}$ & $\mathrm{Mg}$ & $\mathrm{Na}$ & $\mathrm{K}$ & $\mathrm{P}$ \\
0,489 & 0,097 & 75,882 & 0,003 & 0,113 & $2.191,04$ & $5.299,20$ & 150,441 & 110,367 & 3,00 \\
$(0,022)$ & $(0,012)$ & $(2,714)$ & $(0,0006)$ & $(0,040)$ & $(64,765)$ & $(57,050)$ & $(0,163)$ & $(0,737)$ & $(0,00)$ \\
\hline
\end{tabular}

Valor entre parênteses refere-se ao desvio padrão.

A análise química elementar revelou grandes quantidades de $\mathrm{Mg}, \mathrm{Ca}$ e $\mathrm{Na}$, respectivamente, no lignossulfonato, ficando evidenciado que se trata de um lignossulfonato à base de cálcio e magnésio.

$\mathrm{O}$ alto teor de $\mathrm{Mg}, \mathrm{Na}$ e $\mathrm{Ca}$, sugere alta afinidade com a água o que pode gerar maior inchamento e absorção de água em painéis de madeira aglomeradas.

Os cátions, de modo geral, têm afinidade com substâncias ou elementos de cargas negativas, como as hidroxilas presentes nas paredes celulares da madeira.

Entretanto, apresenta também características semelhantes ao lignossulfonato de amônio, cuja extração não foi possível, porém, de acordo com Bartholomew e Kirkhan (1960), é um cátion de importância e ocupa o complexo coloidal, apresentando uma dinâmica muito grande, e seu teor em determinado tempo depende muito das condições de umidade, temperatura, $\mathrm{pH}$, entre outros.

$\mathrm{O} \mathrm{Mg}$ com propriedade divalente, apresenta alta mobilidade e alta capacidade de agregação de moléculas em substratos, funcionando assim, como agente agregante, embora também reaja com as hidroxilas, entretanto, pode se ligar formando ligações iônicas.

$\mathrm{O} \mathrm{Ca}$ e o Na também agregam substâncias quando fora de soluções aquosas e apresentam importância no complexo coloidal de substâncias, embora sem capacidade agregante devido à alta afinidade com a água, em função do seu alto raio iônico hidratado, tendendo a dispersar partículas coloidais.

Espectroscopia de infravermelho do lignossulfonato

Os lignossulfonatos são polímeros complexos que contêm diferentes grupos funcionais tais como grupos sulfônicos, metoxílicos, fenólicos, carboxílicos, cetônicos, entre outros. As propriedades funcionais destes dependem fortemente da natureza dos grupos funcionais que formam seu esqueleto.

Conforme a Figura 1, o lignossulfonato segue um padrão comum, com um sinal largo 3600$3300 \mathrm{~cm}^{-1}$ correspondente aos grupos hidroxílicos de ácidos fenólicos e carboxílicos e vários sinais com intensidades variáveis na região de impressão digital $\left(1900 \mathrm{a} 800 \mathrm{~cm}^{-1}\right)$.

Os principais sinais observados estão de acordo com os dados encontrados em outros trabalhos sobre lignina, lignina técnica e lignossulfonatos (HU et al., 2012; LEE, 2013).

O sinal de absorção da vibração de estiramento em $3350 \mathrm{~cm}^{-1}$, correspondentes aos grupos hidroxílicos, assim como os sinais em $1,605 \mathrm{~cm}^{-1}, 1,512 \mathrm{~cm}^{-1}$ e $1424 \mathrm{~cm}^{-1}$ foram atribuídos para vibrações de anéis aromáticos. Os sinais em $1455 \mathrm{~cm}^{-1}$ e $1372 \mathrm{~cm}^{-1}$ foram devidos às vibrações de dobramento de $\mathrm{CH}_{2}$, e o sinal de absorção em $1030 \mathrm{~cm}^{-1}$ foi atribuído a grupos hidroximetílicos. 
Figura 1 - Espectro do lignossulfonato sem modificação, diluído a 45\% e liofilizado.

Figure 1 - Lignosulfonate spectrum without modification, diluted to $45 \%$ and lyophilized.

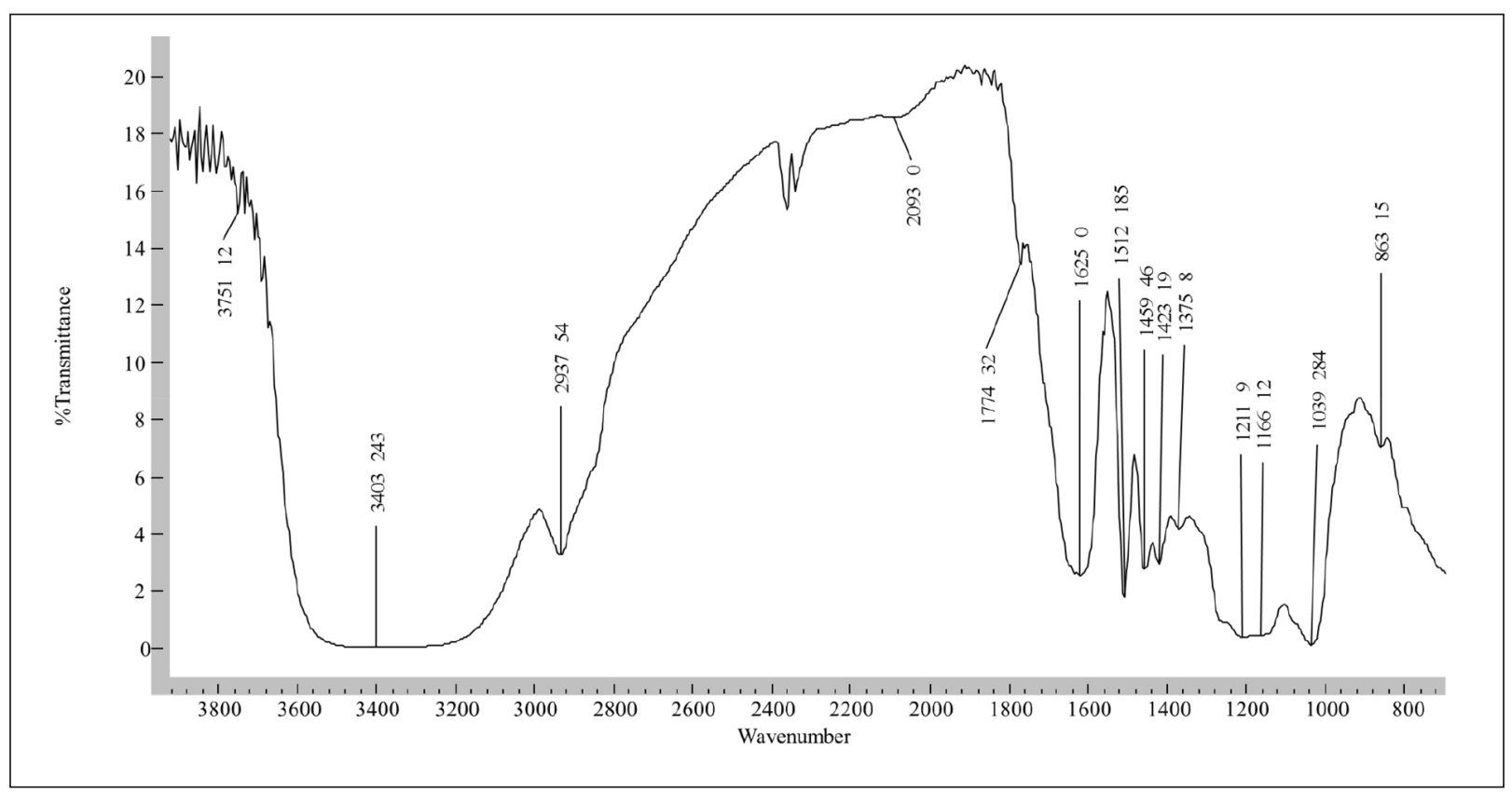

Outros sinais característicos foram apresentados em $1774 \mathrm{~cm}^{-1}$ que são correspondentes ao estiramento de grupos acetoxi aromáticos, $1625 \mathrm{~cm}^{-1}$ de estiramento grupos de carbonila de cetonas ou aldeídos não conjugados, $1212 \mathrm{~cm}^{-1}$ de estiramento de $\mathrm{C}-\mathrm{C}, \mathrm{C}-\mathrm{O}$ e $\mathrm{C}=\mathrm{O}, 1167 \mathrm{~cm}^{-1}$ de deformação de $\mathrm{CH}$ no plano. Os sinais para o grupo $\mathrm{SO}_{3} \mathrm{H}$ são vistos em $1040 \mathrm{~cm}^{-1}$ e a $863 \mathrm{~cm}^{-1}$.

Vieira (2014) avaliando a extração, reatividade e toxidez de extratos tânicos da casca de Pinus oocarpae Pinus caribaea submeteu à espectroscopia, amostras do adesivo ureia-formaldeído e os resultados mostraram que não há presença de substâncias aromáticas na estrutura do adesivo e que ao se adicionar o tanino das duas espécies de pinus ao adesivo ureia-formaldeído, os espectros indicaram que houve modificações na região de $1518-1647 \mathrm{~cm}^{-1}$, com o surgimento de sinais que caracterizam substâncias aromáticas, presentes nas duas espécies, evidenciando que houve reação ao se adicionar tanino à ureia-formaldeído.

Espectros de ressonância magnética nuclear

Normalmente os espetros de ligninas são extremamente complexos, embora as técnicas de aquisição tenham evoluído, assim como a frequência dos equipamentos. As ligninas, de modo geral, são insolúveis em solventes orgânicos neutros e desta forma são empregadas reações como a acetilação para facilitar a aquisição dos espectros, por exemplo, solubilizando com clorofórmio (PU; HALLAC; RAGAUSKAS, 2013).

Os resultados da Ressonância Magnética Nuclear de $\mathrm{H}^{+}$para o lignossulfonato e suas modificações com diferentes agentes catalisadores e endurecedores são apresentados nas Figuras 2 a 3 e na Tabela 6. Neste caso, o lignossulfonato não foi acetilado; por isso, os espectros foram registrados quando utilizados o solvente DMSO.

A Figura 4 (88\% de LS + 2\% de sulfato de amônia) não evidenciou mudanças significativas no espectro. O espectro da Figura $3(70 \%$ de LS $+30 \%$ de formaldeído) evidenciou aumento das intensidades dos sinais entre 4,3 - 5,2 ppm e aumento de número de acetatos assim como contaminantes. Entre 8,0 9,0 , há também indicativo de prótons formílicos. 
Figura 2 - Espectro do lignossulfonato com os principais sinais em evidência.

Figure 2 - Lignosulfonate spectrum with the main signs in evidence.

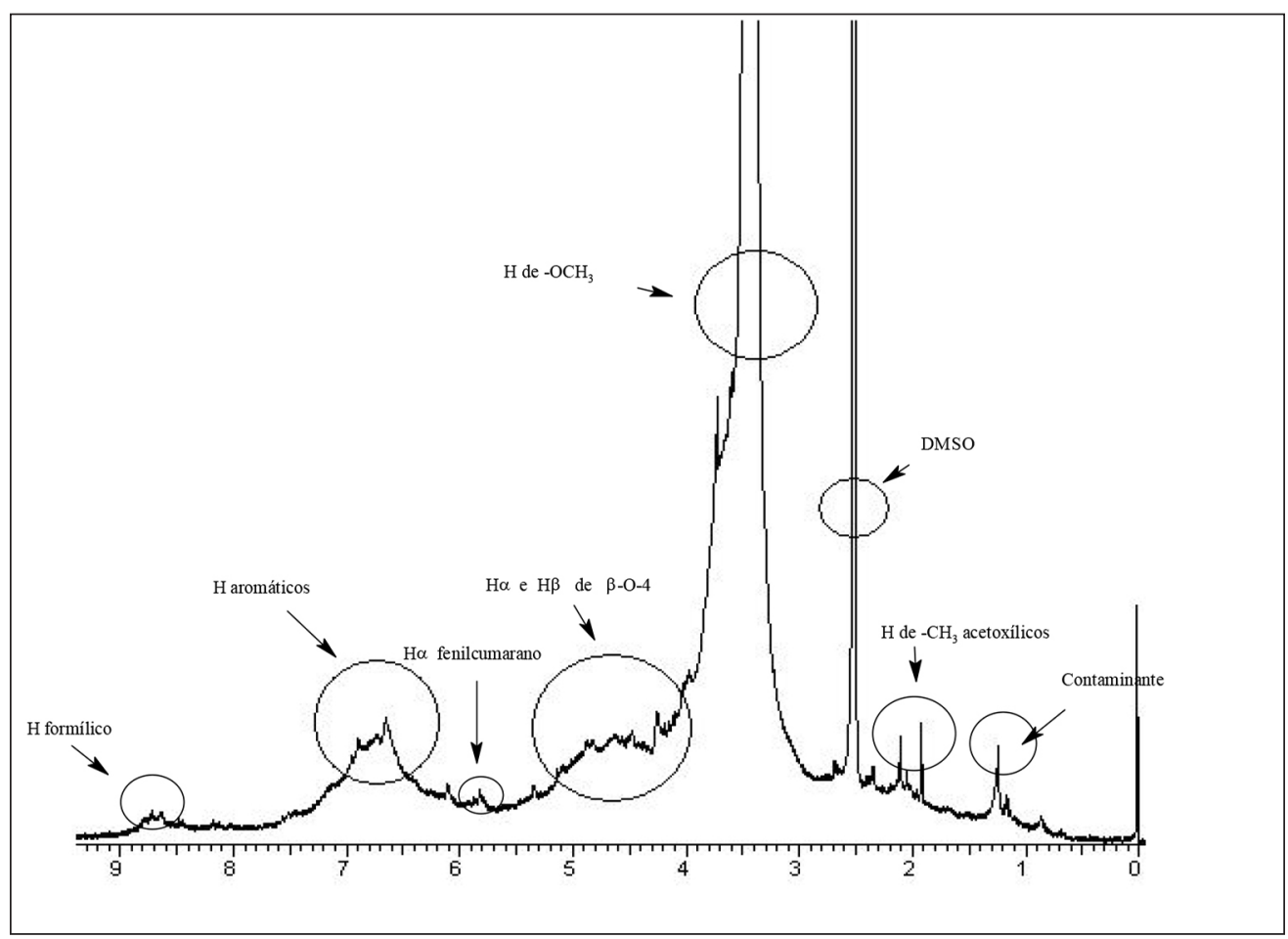

Figura 3 - Espectro de 70\% lignossulfonato e $30 \%$ de formaldeído com os principais sinais.

Figure 3 - Spectrum of lignosulfonate $70 \%$ and $30 \%$ of formaldehyde with the main signal.

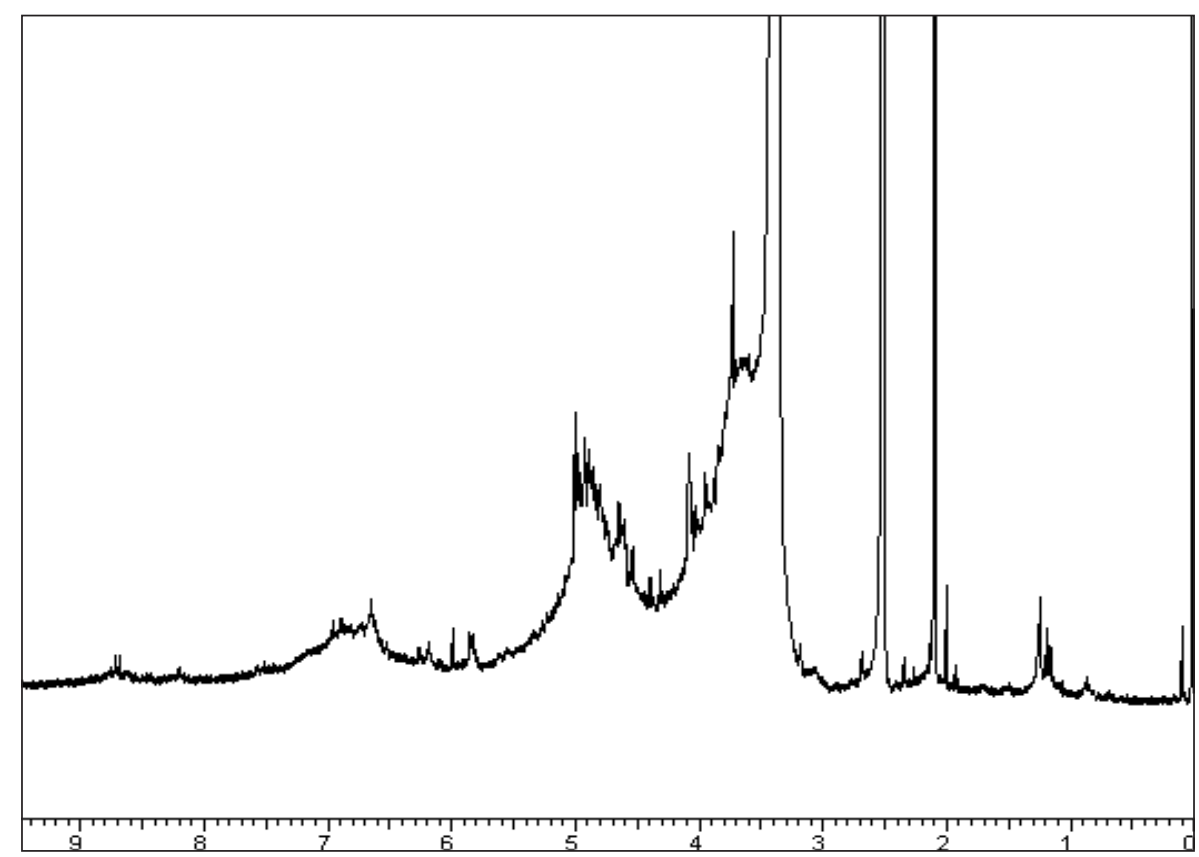


Figura 4 - Espectro de $88 \%$ lignossulfonato e $2 \%$ sulfato de amônia com os principais sinais.

Figure 4: Spectrum of $88 \%$ lignosulfonate and $2 \%$ ammonium sulfate with the main signs.

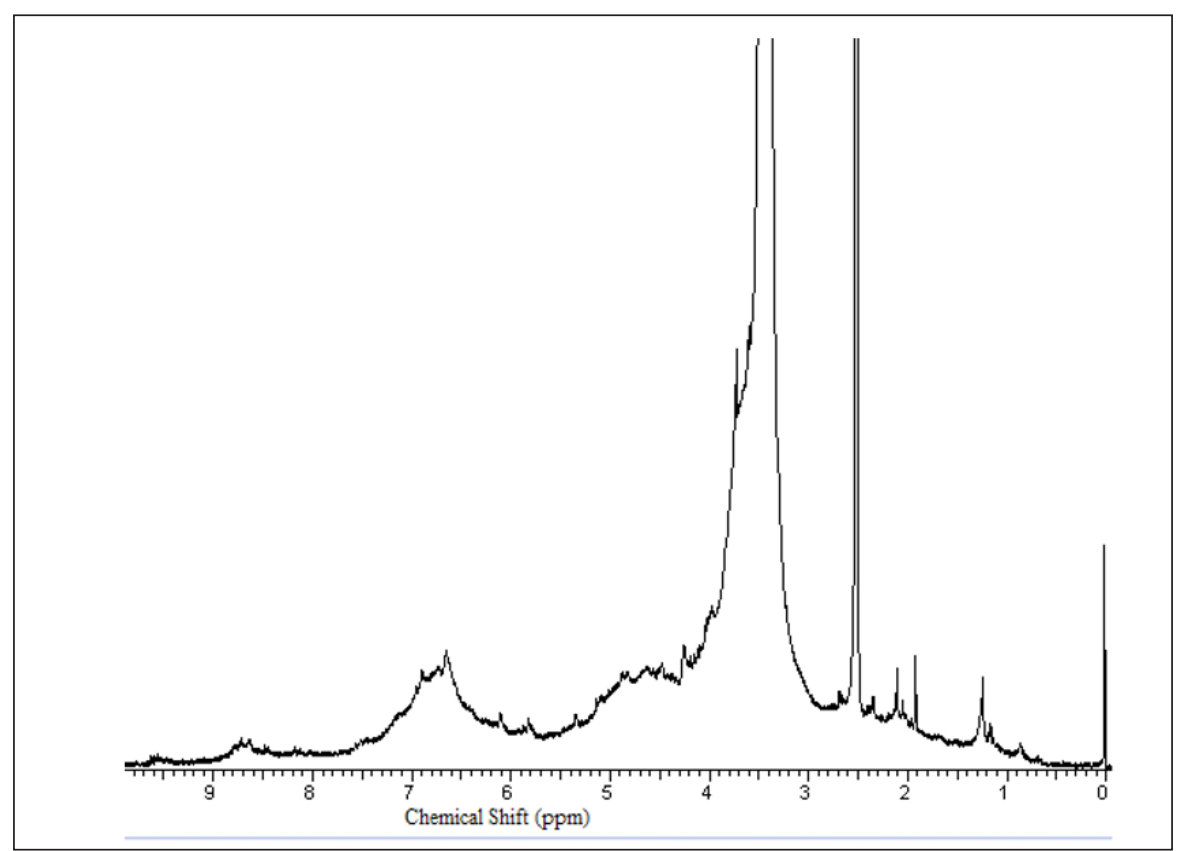

Tabela 6 - Atribuição dos sinais de RMN de H do lignossulfonato e de suas misturas.

Table 6 - Allocation of H-NMR signals from lignosulfonate and mixtures.

\begin{tabular}{lc}
\hline \multicolumn{1}{c}{ Deslocamento Químico } & Atribuição \\
\hline $0,50-1,50$ & Hidrocarboneto contaminante \\
$1,90-2,50$ & Acetatos \\
2,62 & Prótons benzílicos da estrutura $\beta-\beta$ \\
$3,00-3,70$ & Prótons de grupos metoxílicos \\
$4,00-4,50$ & H $\gamma$ de várias estruturas \\
$4,40-5,10$ & H $\gamma$ das estruturas $\beta$-O-4 e $\beta-5$ \\
$4,40-5,10$ & H $\beta$ da estrutura $\beta-O-4$ \\
$4,40-5,10$ & Ho das estruturas $\beta$ - $\beta$ e H $\beta$ benzílico de estrutura $\alpha-O-4$ \\
5,80 & H $\alpha$ de estrutura $\beta-5$ \\
6,10 & H $\alpha$ das estruturas $\beta-O-4$ e $\beta-1$ \\
$6,90-7,70$ & Prótons Aromáticos (prótons vinílicos) \\
$6.90-7,70$ & Prótons aromáticos de unidades benzaldeídicas \\
$8,00-9,00$ & Prótons formílicos \\
\hline
\end{tabular}

A interpretação dos espectros permitiu a confirmação de que o material é realmente um lignossulfonato, tendo sido observadas as atribuições características de lignina.

A Figura 5 apresenta a estrutura dos principais grupos e ligações em função das alterações dos polímeros. 
Silva, G. C.; Lelis, R. C. C.; Oliveira, G. L.; Silva, B. C.; Lossano, W. C. S.; Abreu, H. S.

Figura 5 - Estruturas e ligações ocorridas nos polímeros obtidos na RMN do lignossulfonato.

Figure 5 - Structures and bonds occurring in the polymers obtained in NMR lignosulfonate.

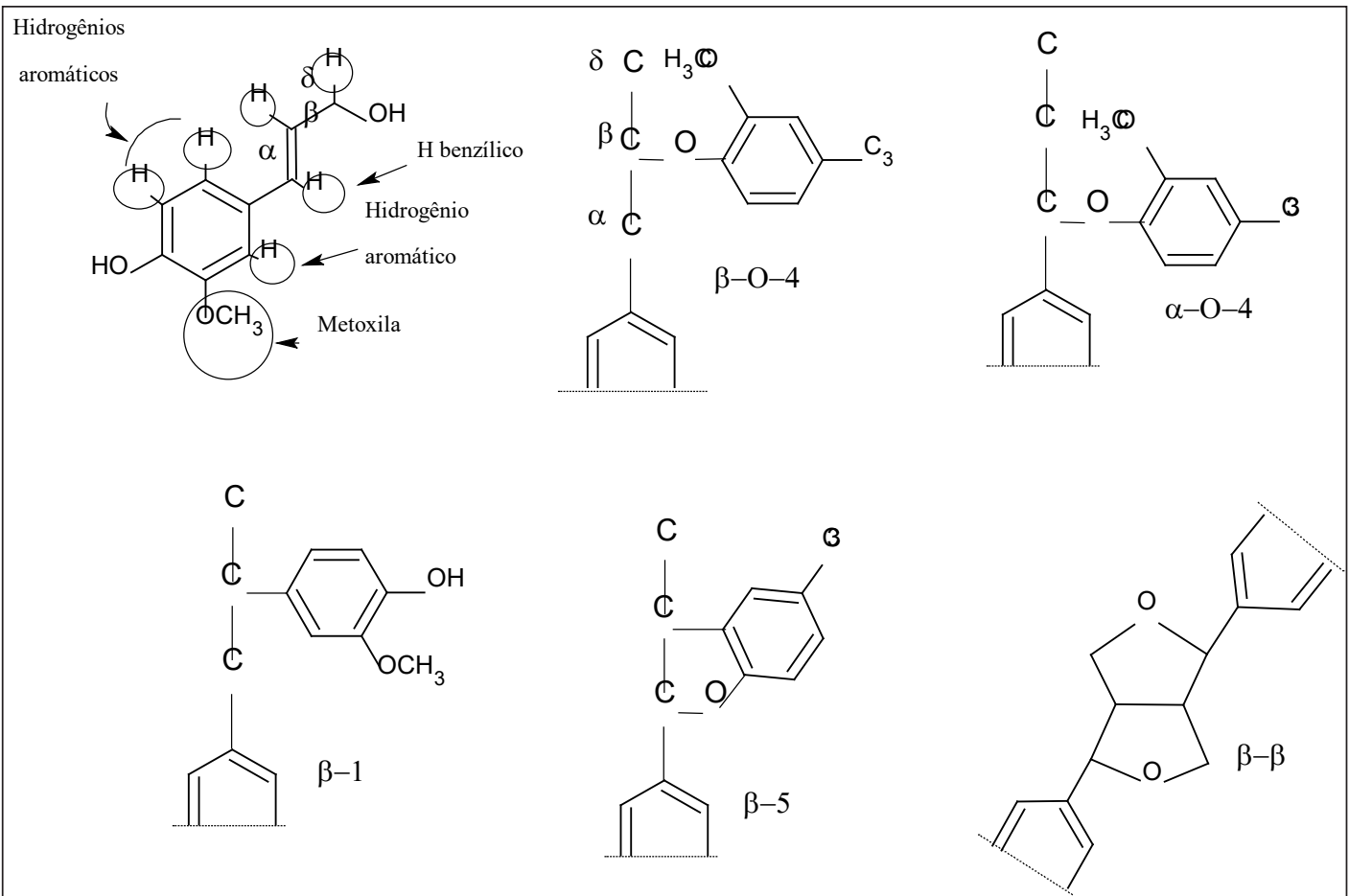

\section{Conclusões}

Nas análises do adesivo ureia-formaldeído em relação à mistura com o lignossulfonato, as principais mudanças ocorrem na redução da viscosidade $\mathrm{pH}$, teor de sólidos e não formação da fase gel.

De acordo com os espectros e a ressonância aplicada ao lignossulfonato, verificou-se que o mesmo apresenta as características estruturais da lignina e, em composição com os catalisadores (sulfato de amônia e formaldeído), não geram alterações que reflitam em melhorias para prováveis propriedades tecnológicas em painéis de madeira.

Novos estudos devem ser implementados com o lignossulfonato, como material natural, obtido a partir de resíduo industrial, pois tendo apresentado resultados significativos em substituição ao adesivo sintético, abre-se um novo caminho, que além do ganho ambiental, pode gerar grande economia em relação aos produtos convencionais comercializados atualmente.

Até $50 \%$ de diluição, com base nas propriedades ligantes, o lignossulfonato apresenta bons resultados como adesivo, ou substituição em parte deste com adesivo sintético.

\section{Agradecimentos}

À CAPES pela concessão da bolsa de estágio doutoral (PDSE).

\section{Referências}

AMERICAN SOCIETY FOR TESTING MATERIALS. ASTM D1200. Standard Test Method for Viscosity by Ford Viscosity Cup. In: ANNUAL Book of ASTM Standards. Washington, 2014.

ASSOCIAÇÃO BRASILEIRA DE NORMAS TÉCNICAS. ABNT NBR 14810-1: Painéis de partículas de média densidade. Rio de Janeiro, 2013. 
ALMEIDA, R. R. Colagem de chapas de madeira aglomerada com adesivos à base de taninos da casca de Pinus oocarpa Schiedeex Schltdl. 2010. 50 f. Dissertação (Mestrado em Ciências) - Universidade Federal Rural do Rio de Janeiro, Seropédica, 2010.

BARTHOLOMEW, W. V.; KIRKHAN, D. Mathematical description and interpretations of culture induced soil nitrogen changes. In: INTERNATIONAL CONGRESS OF SOIL SCIENCE, 7., 1960, Madison. Proceedings... Madison: International Soil Science Society, 1960. v. 2. p. 471-477.

BRITO, E. O. Produção de chapas de partículas de madeira a partir de maravalhas de Pinus elliottivar. elliottii plantado no Sul do Brasil. 1995. 120 f. Tese (Doutorado em Engenharia Florestal) Universidade Federal do Paraná, Curitiba, 1995.

CAMARGO, F. A. Obtenção, caracterização e estudo de biodegradação de blendas de poli (3-hidroxibutirato-co-valerato)/(PHBV) com lignina de bagaço de cana de açúcar. 2003. $115 \mathrm{f}$. Dissertação (Mestrado em Engenharia Química) - Universidade Estadual de Campinas, Campinas, 2003.

CARVALHO, A. G.; LELIS, R. C. C.; NASCIMENTO, A. M. Avaliação de adesivos à base de taninos de Pinus caribaea var. bahamensis e de Acaciamearnsii na fabricação de painéis aglomerados. Ciência Florestal, Santa Maria, v. 24, n. 2, p. 479-489, 2014.

EL MANSOURI, N. E.; SALVADÓ, J. Structural characterization of technical lignins for the production of adhesives: Application to lignosulfonate, kraft, soda-anthraquinone, organosolv and ethanol process lignins. Industrial Crops and Products, Amsterdam, v. 24, n. 1, p. 8-16, 2006.

GODA, A. C. M. et al. Lignosulfonato Melbar. Boletim e Catálogo Técnico. São Paulo: Melbar Produtos de Lignina, 2000. 22 p.

GONÇALVES, F. G. Painéis aglomerados de madeira de Acacia mangiumcom adesivos de ureiaformaldeído e tanino em pó da casca de Acacia mearnsii. 2012. 105 f. Tese (Doutorado em Ciências) - Universidade Federal Rural do Rio de Janeiro, Seropédica, 2012.

GUIMARÃES JUNIOR, J. B. et al. Efeito do teor da parafina nas propriedades físico-mecânicas de painéis aglomerados de Pinus oocarpa. Ciência da Madeira, Pelotas, v. 4, n. 1, p. 72-82, 2013.

HERNANDEZ, J. A. Lignina organosolv de Eucalyptus dunnii Maiden, alternativa para a sintese de adesivos de poliuretano para madeira. 2007. 93 f. Tese (Doutorado em Engenharia Florestal) Universidade Federal do Paraná, Curitiba, 2007.

HU, L. et al. Lignosulfonate-based phenolic foam. BioResources, North Carolina, v. 7, n. 1, p. 554-564, 2012.

IWAKIRI, S. Painéis de madeira reconstituída. Curitiba: FUPE, 2005. 254 p.

IWAKIRI, S. et al. Produção de painéis aglomerados de alta densificação com uso de resina melaminaureia-formaldeído. Cerne, Lavras, v. 11, n. 4, p. 323-328, 2005.

LEE, D. Preparation of a sulfonated carbonaceous material from lignosulfonate and its usefulness as an esterification catalyst. Molecules, Basel, v. 18, n. 1, p. 8168-8180, 2013.

LELIS, R. C. C. ZurBedeutung der kerninhaltsstoffeobligatorischverkernternadelbaumartenbei der herstellung von feuchtebeständigen und biologischresistentenholzspanplatten, am beispiel der douglasie (Pseudotsuga menziesii Mirb. Franco). 1995. 249 f. Diplomarbeit (Doktor der Forstwissenschaft) - Universität Göttingen, Germany, 1995.

MELO, R. R. Propriedades físico-mecânicas e resistência a biodeterioradores de chapas aglomeradas constituídas por diferentes proporções de madeira e casca de arroz. 2009. 77 f. Dissertação (Mestrado em Engenharia Florestal) - Universidade Federal de Santa Maria, Santa Maria, 2009. 
PU, Y.; HALLAC, B.; RAGAUSKAS, A. J. Plant biomass characterization: application of solutionand solid-state nmr spectroscopy in aqueous pretreatment of plant biomass for biological and chemical conversion to fuels and chemicals. New York: Charles E. Wyman; John Wiley \& Sons, 2013.

RAZERA, D. L. Estudo sobre as interações entre as variáveis do processo de produção de painéis aglomerados e produtos moldados de madeira. 2006. 157 f. Tese (Doutorado em Ciências Florestais) Universidade Federal do Paraná, Curitiba, 2006.

VIEIRA, M. C. Colagem de painéis OSB com adesivos à base de taninos da casca de Pinus oocarpa Schiede ex Schltdl. 2010. 64 f. Dissertação (Mestrado em Ciências Ambientais e Florestais) - Universidade Federal Rural do Rio de Janeiro, Seropédica, 2010.

VIEIRA, M. C. Extração, reatividade e toxidez de extratos tânicos da casca de Pinus oocarpae Pinus caribaea var. bahamensis. 2014. 133 f. Tese (Doutorado em Ciências Ambientais e Florestais) Universidade Federal Rural do Rio de Janeiro, Seropédica, 2014. 